\section{$\$$ Research Square}

Preprints are preliminary reports that have not undergone peer review.

They should not be considered conclusive, used to inform clinical practice,

or referenced by the media as validated information.

\title{
The impact of 100 days of Covid-19 lock-down on the emotional health of school children in Chennai, India
}

Cheri Mathews John ( $\sim$ Cherimjohn@gmail.com )

Apollo Speciality Hospital, Chennai, India https://orcid.org/0000-0003-3066-7423

Deepa Elizabeth Mathew

Apollo Speciality Hospital, Chennai, India

Natasha Susan John

ESIC Medical College and PGIMSR, Chennai, India

Joe Johnson

Five Boroughs NHS trust, United Kingdom

Sanju George

Rajagiri hospital, Aluva, India

\section{Research Article}

Keywords: Covid-19, mental health, depression, mood and feelings questionnaire

Posted Date: September 18th, 2020

DOI: https://doi.org/10.21203/rs.3.rs-79649/v1

License: (c) (i) This work is licensed under a Creative Commons Attribution 4.0 International License. Read Full License 


\section{Abstract}

Introduction: Public health measures taken to prevent the spread of the COVID-19 pandemic can potentially impact the mental health of children.

Aims: To assess the prevalence and risk factors of childhood depression during the Covid-19 lock-down.

Methods: After 100 days of lock-down, a survey questionnaire was sent by WhatsApp to parents of school-aged children (5-16 years) in Chennai. The Short Mood and Feelings questionnaire was employed as an objective screening tool to assess depression, with a score of 12 used as the cut-off.

Results: There were 874 responses. The incidence of childhood depression was $13.7 \%$. Boys were less likely to be depressed than girls. Eleven- to 16 -year-olds were more likely to be depressed than 5- to 10-year-old children. Children who had more than 4 hours online education had a higher likelihood of depression. Children who used a cell phone for online classes had a higher likelihood of depression compared to other devices, such as tabs or laptops. Children who slept less than 8 hours a day had a higher likelihood of depression. Children who either did not sleep in the afternoon or slept less than 1 hour had a lower likelihood of depression. Children who were interacting with family over 1 hour per day had a lower likelihood of depression.

Conclusions: Overzealous online education, lack of adequate sleep and failure to spend quality time with the family can negatively impact the mental health of children. The impact of Covid-19 on the emotional health of children should be addressed by public policy makers and health care professionals.

\section{Introduction}

The COVID-19 global pandemic will probably unearth significant mental health issues in children in both developing and developed nations. In response to recommended measures of physical and social distancing to mitigate person-to-person transmission, most countries decided to close schools as part of a physical distancing policy to slow transmission and ease the burden on health systems. U.N. Secretary-General Antonio Guterres said that the coronavirus pandemic has led to the largest disruption of education in history, with schools closed in more than 160 countries in mid-July, affecting over 1 billion students. These school closures affected the education of $80 \%$ of children worldwide. Psychologists feel that the closure of schools for a prolonged period of time could have detrimental social and health consequences for children living in poverty and could potentially exacerbate existing inequalities.

The slew of measures implemented by the Government of India included closing schools and colleges, shopping malls and theatres, religious gatherings, and limiting the number of people getting out of their homes, among other measures. Many of these public health measures had to be implemented relatively quickly, which could have impacted the emotional wellbeing of school children negatively. We carried out a survey to ascertain the mental health status of school children during the lockdown in Chennai, Tamil Nadu, South India. Chennai is a large metropolitan city and the capital of Tamil Nadu, a southern state of India with a population of approximately 72 million people and a human development index of 0.544 (ranked $6^{\text {th }}$ highest in India).

\section{Methods}

Data were collected through a voluntary anonymous self-report questionnaire sent out by WhatsApp after 100 days of lock-down. Ethics approval was obtained for this research study. The survey questionnaire was created in Google forms and was electronically distributed through WhatsApp to parents across Chennai. We used a cut-off score of 12 for the short Mood and Feelings questionnaire (MFQ), which is the cut-off recommended by the Child Outcomes Research Consortium, United Kingdom. We collected and analyzed 874 responses.

\section{$\underline{\text { Statistical analysis }}$}

All data were analyzed using Statistical Package for Social Science (SPSS, version 17) for Microsoft Windows. Descriptive statistics are presented as numbers and percentages. The data are expressed as the mean and SD. A chi-squared test was used for comparison between two attributes with $\mathrm{OR} 95 \% \mathrm{Cl}$. Multiple logistic regression was used. A two-sided $p$ value $<0.05$ was considered statistically significant.

\section{Results}

There were 874 responses with nearly equal sex distributions (male 49.8\%, female $50.2 \%$ ). The incidence of depression was $13.7 \%$ based on the short version of the Mood and Feelings Questionnaire (MFQ) developed by Adrian Angold and Elizabeth J. Costello in 1987 (Angold et al., 1995; Costello \& Angold, 1988). Boys were less likely to be depressed than girls (OR 0.495, P value 0.000 ). Eleven- to 16-year-olds were more likely to be depressed than 5 - to 10 -year-old children (OR 1.519, P 0.035). Children who had more than 4 hours online education had a higher likelihood of depression (OR $1.757, \mathrm{P}=0.037)$. Children who used a cell phone for online class had a higher likelihood of depression than children using devices such as tab or laptop (OR 2.142, P 0.000). Children who slept less than 8 hours a day had a higher likelihood of depression (OR 2.441, P 0.000). Children who either did not sleep in the afternoon or slept less than 1 hour had a lower likelihood of depression than children who slept more than one hour in the afternoons (OR 0.522, P 0.010). Children who interacted with family over 1 hour per day were less likely to have depression (OR 2.985, P 0.000).

\section{Discussion}

UNESCO estimates that over $90 \%$ of enrolled learners (over a billion young people) worldwide are now out of education. Not much is known about the longterm impact of large-scale disease outbreaks on the mental health of children and adolescents [1]. Population studies have reported prevalence rates of depressive disorders in children ranging between $0.4 \%$ to $2.5 \%$ in children and $0.4 \%$ to $8.3 \%$ in adolescents [2,3]. In our study, we employed a cut-off score of 
12 for the short Mood and Feelings questionnaire (MFQ), which is the cut-off recommended by the Child Outcomes Research Consortium, United Kingdom [4]. It is a validated screening tool for depression in children. Boys were less likely to be depressed than girls (OR 0.495, P value 0.000). Eleven- to 16-year-olds were more likely to be depressed than 5 - to 10 -year-old children (OR 1.519, P 0.035). Our survey revealed the incidence of depression to be $13.7 \%$, indicating that children are likely to be experiencing increasing depression exacerbated by the pandemic and the lock-down. Fear experienced by children can include the types of fears that are similar to that experienced by adults, which would include fear of dying, a fear of close relatives dying, or a fear of what it means to be admitted to hospital.

We tried to analyze potential causes and lifestyle issues contributing to childhood depression. a) Online classes

With regard to online classes, $41.2 \%$ had $1-2$ hours of online classes per day, $40.2 \%$ had $3-4$ hours a day, $9 \%$ had $5-6$ hours, $2 \%$ had more than 6 hours a day, and $7.6 \%$ had no online classes. Children who had more than 4 hours online education had higher depression (OR 1.757, P= 0.037) (Table 1). Children who used a cell phone for online class had higher depression than children using devices such as tab or laptop (OR 2.142, P 0.000) (Table 2).

b) Screen time

Excluding online classes, the amount of screen time spent by children on television, laptops, cell phones, and video games was as follows: $36.4 \%$ spent $2-4$ hours, $31.1 \%$ spent $1-2$ hours, $14.4 \%$ spent $4-6$ hours, $14.1 \%$ spent less than 1 hour, and $4 \%$ spent $6-8$ hours. This is clearly in excess of the screen time limit recommended by the $\mathrm{WHO}$, which is two hours a day [5]. There was no statistical significance for the relationship between screen time (excluding online classes) and depression.

c) Physical exercise

With regard to physical exercise, $40.6 \%$ spent less than 30 minutes on exercise, $25.5 \%$ spent 30 minutes to 1 hour, $18 \%$ did no exercise, $12.2 \%$ did $1-2$ hours and $3.7 \%$ did $2-4$ hours. The recommendations of the WHO are for children and youth aged 5-17 to accumulate at least 60 minutes of moderate- to vigorousintensity physical activity daily [6]. However, there was no statistical significance for the relationship between physical exercise and depression.

d) Sleep

Sleeping patterns were variable. A total of $53.5 \%$ had $8-10$ hours of sleep, $38.3 \%$ had $6-8$ hours of sleep, $5.4 \%$ had $10-12$ hours of sleep and $2.8 \%$ had less than 6 hours of sleep. Children who slept less than 8 hours a day had higher depression (OR 2.441, P 0.000) (Table 3). With regard to afternoon naps, 77.7\% did not sleep in the afternoons, $11.8 \%$ slept $1-2$ hours and $9.6 \%$ slept less than 1 hour and $0.9 \%$ slept $2-4$ hours. Children who either did not sleep in the afternoon or slept less than 1 hour had less depression than children who slept more than one hour in the afternoons (OR 0.522, P 0.010) (Table 4). Sleep disturbances are not just a symptom or by-product of depression, but in many patients, insomnia contributes to depression onset and/or maintenance [7].

e) Interaction with family members

With respect to interaction with family members, $55.4 \%$ spent $2-4$ hours, $31.1 \%$ spent $1-2$ hours, $11.8 \%$ spent $<1$ hour and $1.7 \%$ spent no time interacting with their own family. Statistical analysis demonstrated that the children who interacted with family members over 1 hour per day were less likely to have depression (OR 2.985, P 0.000) (Table 5). There is evidence in the literature suggesting that negative family interactions contribute to childhood depression $[8,9]$. We also analysed interaction with friends, but the results were not statistically significant.

If schools have closed as part of necessary measures, then children may no longer have that sense of structure and stimulation that is provided by that environment, and they end up with less opportunity to be with their friends and get that social support that is essential for good mental well-being.

While there is some research on the psychological impact of severe acute respiratory syndrome (SARS) on patients and health-care workers, not much is known about the effects on ordinary citizens. Evidence is especially scarce in children and adolescents. COVID-19 is much more widespread than SARS and other epidemics on a global scale. As the pandemic continues, it is important to support children and adolescents facing bereavement and issues related to parental unemployment or loss of household income. There is also a need to monitor young people's mental health status over the long term and to study how prolonged school closures, strict social distancing measures, and the pandemic itself affect the wellbeing of children and adolescents.

Although the current school closures differ from summer holidays in that learning is expected to continue digitally, the closures are likely to widen the learning gap between children from lower-income and higher-income families. Children from low-income households live in conditions that make home schooling difficult. Online learning environments usually require computers and a reliable internet connection [10].

We anticipate a considerable increase in anxiety and depressive symptoms among people who do not have pre-existing mental health conditions, with some experiencing post-traumatic stress disorder in due course [11]. There is already evidence that this possibility has been underrecognized in China during the current pandemic [12].

Public health policy makers must address the psychological impact of this crisis on children. Collective trauma events have short- and long-term implications, including post-traumatic stress, anxiety and behavioural disorders [13]. Children in poverty are particularly vulnerable because of underlying psychosocial stressors (e.g., home instability) and developmental and behavioural disorders [9].

Psychologists have noticed three emerging patterns in school children during this pandemic [14]. A first group of schoolchildren seem to prosper mainly because they are at home in a quieter and more conducive environment where they can thrive with the structure and support provided by their parents. These children enjoy online learning, and notably, they are not exposed to any adverse events, such as bullying or social exclusion. Similarly, there exists a second group of children who seem to be mildly affected in an adverse manner. Their developmental opportunities are on hold, as due to relatively fewer available resources for online learning, they are unable to interact with peers and thereby improve their social skills and no longer have access to practice what they 
were learning in a social setting. The third group includes children who unfortunately find themselves in families with an increasingly negative environment, and these children may potentially feel deprived of the safe haven offered by their schools.

However, it must be noted that our cohort of school children had no pre-existing mental health disorders. This may be due to less awareness of psychological symptoms and emotional disturbance in India. A sample size of 874 children gives fairly valid and generalizable findings. However, as this study was limited to Chennai, it could be argued that these findings may not be generalizable to other parts of a diverse country such as India. Nevertheless, having seen the socio-demographic spread of our sample, we make the case that these findings are representative of the wider population of India and will offer useful pointers to public health policy makers, especially when dealing with future pandemics.

\section{Conclusions}

Public health policy makers and health care professionals need to acknowledge that pandemics (especially when associated with lock-down) can potentially negatively impact the psychological well-being of school-age children. In the event of similar future pandemics, strategies need to be in place to safeguard the psychological well-being of individuals by offering them timely and appropriate psychological support, as well as taking the appropriate steps in the effective management of those already affected psychologically.

\section{Declarations}

Competing interests: None

Contribution

DEM and CMJ conceptualized the paper, drafted the initial manuscript, and critically reviewed and revised the manuscript. NSJ drafted the proforma, organised data collection and helped draft the initial manuscript. JJ and SG critically reviewed and finalized the manuscript. All authors approved the final manuscript as submitted and agree to be accountable for all aspects of the work.

Ethics committee approval was obtained for this survey from Apollo Hospitals, Chennai (AVH-C-S-008/07-20)

Financial declaration: No funding was received for this study

\section{References}

1. Lee J. Mental health effects of school closures during COVID-19 Lancet Child Adolesc Health. 2020;4(6):421.

2. Anderson JC, McGee R. Co-morbidity of depression in children and adolescents. In: Handbook of Depression in Children and Adolescents. Eds Reynolds WM Johnson HF, New York, Plenum, 1994; pp 581-601.

3. Lewinsohn PM, Clarke GN, Seeley JR, Rohde P. Major depression in community adolescents: Age at onset, episode duration and time to recurrence. J Am Acad Child Adolesc Psychiatry 1994; 33(6): 809-818.

4. Child Outcomes Research Consortium, United Kingdom https://www.corc.uk.net/outcome-experience-measures/mood-and-feelings-questionnaire/ 5. https://www.eyepromise.com/wp-content/uploads/2019/05/Screentime-Recommendation-Chart-Final_AAP-WHO.pdf

6. https://www.who.int/dietphysicalactivity/factsheet_young_people/en/\#: :text=Children\%20and\%20youth\%20aged\%205,physical\%20activity\%20should\%

7. Greg Clarke, Allison G. Harvey The complex role of sleep in adolescent depression Child Adolesc Psychiatr Clin N Am. 2012; 21(2): 385-400.

8. Goodman SH, Gotlib IH Risk for psychopathology in the children of depressed mothers: a developmental model for understanding mechanisms of transmission. Psychol Rev. 1999; 106(3):458-90

9. Sheeber L, Sorensen E Family relationships of depressed adolescents: a multimethod assessment. J Clin Child Psychol. 1998 Oct; 27(3):268-77.

10. Van Lancker W, Parolin Z. COVID-19, school closures, and child poverty: a social crisis in the making. Lancet Public Health. 2020 May;5(5): e243-e244.

11. Cullen W, Gulati G, Kelly BD Mental health in the COVID-19 pandemic. QJM. 2020 May 1;113(5):311-312.

12. Duan L, Zhu G. Psychological interventions for people affected by the COVID-19 epidemic. Lancet Psychiatry 2020; 7(4):300-2

13. Rajmil L, de Sanmamed M-J, Choonara I, et al. Impact of the 2008 economic and financial Crisis on Child Health: A Systematic Review. IJERPH. 2014;11(6):6528-6546

14. Clemens V, Deschamps P, Fegert JM et al. Potential effects of "social" distancing measures and school lockdown on child and adolescent mental health. Eur Child Adolesc Psychiatry 2020 Jun;29(6):739-742

\section{Tables}

Table 1: Hours of online class ( $>4$ hours / <=4 hours) and risk of depression: 


\begin{tabular}{|c|c|c|c|c|c|}
\hline \multicolumn{6}{|l|}{ Crosstab } \\
\hline & & & \multicolumn{2}{|c|}{ Level of Depression score } & \multirow[t]{2}{*}{ Total } \\
\hline & & & Depressed & Not Depressed & \\
\hline \multirow[t]{4}{*}{ The total number of hours of online class per day (on average): } & $>4$ hours & Count & 20 & 77 & 97 \\
\hline & & $\%$ & $20.6 \%$ & $79.4 \%$ & $100.0 \%$ \\
\hline & $<=4$ hours & Count & 100 & 677 & 777 \\
\hline & & $\%$ & $12.9 \%$ & $87.1 \%$ & $100.0 \%$ \\
\hline Total & & Count & 120 & 754 & 874 \\
\hline$\%$ & $13.7 \%$ & $86.3 \%$ & $100.0 \%$ & & \\
\hline
\end{tabular}

$P=0.037$

Odd's ratio $=1.758$

Table 2: Mode of Online Class and risk of depression:

\begin{tabular}{|c|c|c|c|c|c|}
\hline \multicolumn{6}{|l|}{ Crosstab } \\
\hline & & & \multicolumn{2}{|c|}{ Level of Depression score } & \multirow[t]{2}{*}{ Total } \\
\hline & & & Depressed & Not Depressed & \\
\hline \multirow[t]{4}{*}{ Mode of online class: } & Mobile phone & Count & 70 & 298 & 368 \\
\hline & & $\%$ & $19.0 \%$ & $81.0 \%$ & $100.0 \%$ \\
\hline & Others devices & Count & 50 & 456 & 506 \\
\hline & & $\%$ & $9.9 \%$ & $90.1 \%$ & $100.0 \%$ \\
\hline Total & & Count & 120 & 754 & 874 \\
\hline$\%$ & $13.7 \%$ & $86.3 \%$ & $100.0 \%$ & & \\
\hline
\end{tabular}

$P=0.000$

Odd's ratio $=2.142$

Table 3: Hours of sleep ( $<8$ hours / >= 8 hours) and risk of depression:

\begin{tabular}{|c|c|c|c|c|c|}
\hline \multicolumn{6}{|l|}{ Crosstab } \\
\hline & & & \multicolumn{2}{|c|}{ Level of Depression score } & \multirow[t]{2}{*}{ Total } \\
\hline & & & Depressed & Not Depressed & \\
\hline \multirow[t]{4}{*}{ Hours of sleep per night (on average): } & $<8$ hours & Count & 72 & 287 & 359 \\
\hline & & $\%$ & $20.1 \%$ & $79.9 \%$ & $100.0 \%$ \\
\hline & $>=8$ hours & Count & 48 & 467 & 515 \\
\hline & & $\%$ & $9.3 \%$ & $90.7 \%$ & $100.0 \%$ \\
\hline Total & & Count & 120 & 754 & 874 \\
\hline$\%$ & $13.7 \%$ & $86.3 \%$ & $100.0 \%$ & & \\
\hline
\end{tabular}

$P=0.000$

Odd's ratio $=2.441$ 
Table 4: Hours of sleep in the afternoon ( $<1$ hour / > 1 hour) and risk of depression:

\begin{tabular}{|c|c|c|c|c|c|}
\hline \multicolumn{6}{|l|}{ Crosstab } \\
\hline & & & \multicolumn{2}{|c|}{ Level of Depression score } & \multirow[t]{2}{*}{ Total } \\
\hline & & & Depressed & Not Depressed & \\
\hline \multirow[t]{4}{*}{ How many hours does the child sleep in the afternoon (on average)? } & \multirow[t]{2}{*}{ Less than 1 hour } & Count & 96 & 667 & 763 \\
\hline & & $\%$ & $12.6 \%$ & $87.4 \%$ & $100.0 \%$ \\
\hline & \multirow[t]{2}{*}{ More than 1 hour } & Count & 24 & 87 & 111 \\
\hline & & $\%$ & $21.6 \%$ & $78.4 \%$ & $100.0 \%$ \\
\hline Total & & Count & 120 & 754 & 874 \\
\hline$\%$ & $13.7 \%$ & $86.3 \%$ & $100.0 \%$ & & \\
\hline
\end{tabular}

$P=0.010$

Odd's ratio $=0.522$

Table 5: Interaction with family members ( $<1$ hour / > 1 hour) and risk of depression:

\begin{tabular}{|c|c|c|c|c|c|}
\hline \multicolumn{6}{|l|}{ Crosstab } \\
\hline & & & \multicolumn{2}{|c|}{ Level of Depression score } & \multirow[t]{2}{*}{ Total } \\
\hline & & & Depressed & Not Depressed & \\
\hline \multirow[t]{4}{*}{ How much do you interact with your family members each day? } & \multirow[t]{2}{*}{ Less than 1 hour } & Count & 33 & 85 & 118 \\
\hline & & $\%$ & $28.0 \%$ & $72.0 \%$ & $100.0 \%$ \\
\hline & \multirow[t]{2}{*}{ More than 1 hour } & Count & 87 & 669 & 756 \\
\hline & & $\%$ & $11.5 \%$ & $88.5 \%$ & $100.0 \%$ \\
\hline Total & & Count & 120 & 754 & 874 \\
\hline$\%$ & $13.7 \%$ & $86.3 \%$ & $100.0 \%$ & & \\
\hline
\end{tabular}

$P=0.000$

Odd's ratio $=2.985$

Table 6: Variables in the Equation:

\begin{tabular}{|lcccccccccc|}
\hline & & & & & & & & \\
& B & S.E. & Wald & df & Sig. & Exp(B) & $95 \%$ C.I. for EXP(B) \\
\cline { 1 - 9 } & & & & & & & & Lower & Upper \\
\hline Sex & -.674 & .214 & 9.954 & 1 & .002 & .510 & .335 & .775 \\
\hline Age & .396 & .229 & 2.986 & 1 & .084 & 1.485 & .948 & 2.326 \\
\hline Hours of online class & .263 & .317 & .691 & 1 & .406 & 1.301 & .699 & 2.423 \\
\hline Hode of online class & .688 & .214 & 10.365 & 1 & .001 & 1.990 & 1.309 & 3.024 \\
\hline Hours of sleep per night & .736 & .213 & 11.962 & 1 & .001 & 2.088 & 1.376 & 3.168 \\
\hline Interaction with family & -.534 & .273 & 3.814 & 1 & .051 & .587 & .343 & 1.002 \\
\hline Constant & .999 & .246 & 16.535 & 1 & .000 & 2.715 & 1.677 & 4.393 \\
\hline
\end{tabular}

